\title{
PENDAMPINGAN PENERAPAN BIMBINGAN PRIBADI DAN BIMBINGAN BELAJAR MATEMATIKA UNTUK MEMBANGUN RESILIENSI SISWA KELAS 6 SD CAHAYA BANGSA UTAMA
}

\author{
Yustinus Budi Setiawan ${ }^{1}$, Ignatia Esti Sumarah ${ }^{2}$ \\ ${ }^{1}$ SD Cahaya Bangsa Utama, \\ ${ }^{2}$ Program Studi PGSD Universitas Sanata Dharma Yogyakarta \\ ${ }^{1} \mathrm{Jl}$. KH. Muhdi, Maguwoharjo, Sleman, DIY \\ ${ }^{2}$ Mrican, Catur Tunggal, Depok, Sleman, DIY \\ ${ }^{1}$ Email: kapernaum.bs@gmail.com \\ ${ }^{2}$ Email: isumarah@gmail.com
}

\begin{abstract}
ABSTRAK
Di awal tahun ajaran 2018/2019, siswa kelas 6 SD Cahaya Bangsa Utama cenderung mengalami kejenuhan, kebosanan dan kesulitan menghadapi metode belajar drilling dalam rangka menghadapi Ujian Nasional (UN). Mereka kerap mengeluh saat menjawab soal-soal, khususnya soal matematika. Perilaku tersebut apabila dibiarkan dapat menghambat mereka untuk bersikap resilien. Oleh karena itu, tujuan pengabdian ini untuk mendampingi wakil kepala sekolah bagian kesiswaan supaya dapat memberikan bimbingan pribadi dan bimbingan belajar (bekerja sama dengan guru kelas 6 dan guru matematika), agar siswa kelas 6 mengerjakan soal matematika dengan resilien.

Berlandaskan pada teori growth mindset, maka bimbingan pribadi dan bimbingan belajar menjadi sarana bagi siswa untuk memiliki persepsi positif tentang matematika. Mereka pun mengetahui manfaat matematika bagi hidupnya di masa kini maupun masa depan. Teori growth mindset juga menegaskan bahwa talenta dan keahlian seseorang itu bukan berasal dari bawaan sejak lahir, melainkan karena diasah, dilatih, dipelajari; maka bimbingan belajar matematika menumbuhkan resilience atau daya juang siswa, sehingga menjadi bersemangat dan tekun mengerjakan soal-soal matematika.
\end{abstract}

Kata kunci: Bimbingan pribadi, bimbingan belajar, resiliensi.

\begin{abstract}
At the beginning of academic year of 2018/2019, grade 6 students of Cahaya Bangsa Utama Elementary School were inclined to be saturated, bored, and troubled about drilling method for Final Exam preparation. They frequently grumbled when they were doing some tasks, especially math. This behavior inhibits student's learning process and make them less resilient. Therefore, the purpose of the activities of Community Service is to guide vice principal of student affairs to conduct personal guidance program and math tutoring program (assisted by grade 6 teacher and math teacher.

Based on growth mindset theory, personal guidance program facilitates the students to attain positive perception of math. They, accordingly, understand the benefit of math toward their life, both today and future days. Growth mindset theory also underlines that talents and skills are not predetermined at birth, but cultivated through efforts, shaperned and trained; therefore math tutoring may build students' resilience in doing math exercises. Keywords: Personal guidance, tutoring, resilience.
\end{abstract}




\section{PENDAHULUAN}

SD Cahaya Bangsa Utama atau lebih dikenal dengan nama Sekolah Kinderstation Primary berlokasi di jalan K.H. Muhdi Corongan Maguwoharjo, Depok, Sleman, Yogyakarta. SD ini berstatus sebagai sekolah National Plus yang menggunakan IPC (kurikulum internasional) dan kurikulum 2013. IPC singkatan dari International Primary Curriculum dikembangkan oleh perusahaan minyak Shell di Belanda. Awalnya, kurikulum ini dibentuk untuk mengakomodasi kebutuhan pendidikan anak para karyawan Shell yang bekerja di negara lain, dengan memperhatikan konteks keragaman budaya setempat (Noble, 2012). Kekhasan dari kurikulum ini melatih siswa untuk memiliki naluri ilmiah/rasa ingin tahu/scientific sehingga siap menghadapi era globalisasi (Pletser, 2012). Salah satu model pembelajaran yang diterapkan IPC untuk menumbuhkan rasa ingin tahu siswa adalah PBL (Project Based Learning).

IPC dengan model pembelajaran berbasis project (PBL) menjadi kekhasan pembelajaran di kelas 1 sampai kelas 6 SD Cahaya Bangsa Utama. PBL menerapkan proses pembelajaran yang tidak berpusat pada guru, melainkan pada siswa/student-centered learning (Jacobs and Toh-Heng, 2013). Model pembelajaran PBL membiasakan siswa untuk mempelajari sesuatu berdasarkan tema tertentu, mendesain pembelajaran sesuai tema yang dibahas, memecahkan masalah, mengambil keputusan, melakukan investigasi, dan diberi kesempatan bekerja dalam periode waktu yang telah terjadwal untuk menghasilkan produk (Thomas, Mergendoller\& Michaelson, 1999). Sebagai contoh, pada saat siswa kelas 4 diajak membahas tema "Air" maka di akhir proses pembelajaran mereka diharapkan menghasilkan produk berupa beberapa bentuk bangun ruang (= belajar Matematika) yang dapat diisi air sehingga mereka mampu mengerti esensi air yang dapat menyesuaikan dengan ruang yang ada (= belajar IPA). Jadi PBL mengembangkan rasa ingin tahu siswa untuk mengerti esensi air dan mengetahui manfaat dari mempelajari bangun ruang.

Model pembelajaran PBL tidak mendapatkan porsi lebih banyak di kelas 6 sebab seluruh proses pembelajaran di kelas 6 diarahkan untuk mempersiapkan para siswa menghadapi UN. Oleh karena itu metode belajar drilling yang lebih diutamakan. Tujuannya agar siswa mengenali tipe-tipe soal UN dan dapat menjawabnya sesuai dengan durasi waktu yang telah disediakan. Di rumah, orang tua pun mengarahkan mereka untuk mengikuti berbagai macam bimbingan belajar (yang menggunakan metode drilling juga) pada semua mata pelajaran 
yang wajib lulus UN. Ada 3 mapel yang paling menentukan kelulusan UN, yaitu Bahasa Indonesia, IPA, dan Matematika.

Dari hasil pengamatan guru kelas 6 dan guru matematika kepada 13 siswa kelas 6 angkatan 2018/2019 saat mengerjakan soal-soal matematika, mereka kerap mengucapkan pernyataan-pernyataan berikut: “Aku takut nilai matematikaku jelek", "Nanti kalau aku tidak lulus, harus bagaimana?", “I can't do math", atau "math is difficult". Pernyataan-pernyataan tersebut muncul ketika mereka diberi soal-soal matematika yang tingkat kesulitannya tinggi, serta baru menurun frekuensi keluhannya ketika diberikan soal matematika dengan tingkat kesulitan rendah. Saat mereka harus memecahkan soal matematika dalam bentuk cerita (word problem), mereka tidak tekun mengerjakan soal, mudah mengeluh dan cepat menyerah menyelesaikan pengerjaanya.

Pernyataan-pernyataan dan perilaku-perilaku tersebut memotivasi Bapak Yustinus Budi Setiawan (sebagai wakil kepala sekolah bidang kesiswaan) menghubungi Ibu Ignatia Esti Sumarah (dosen PGSD Univesitas Sanata Dharma) di awal Januari 2019. Tujuannya mendiskusikan cara efektif apakah yang dapat dilakukan untuk membantu siswa kelas 6 SD menumbuhkan sikap resilien. Hasil diskusi menyepakati adanya pengabdian dalam bentuk pendampingan supaya wakil kepala sekolah bagian kesiswaan dapat memberikan bimbingan pribadi dan bimbingan belajar (bekerja sama dengan guru kelas 6 dan guru matematika), agar siswa kelas 6 mengerjakan soal matematika dengan resilien.

Kegiatan pendampingan ditujukan untuk: (1) menganalisis assessment permasalan siswa kelas 6, (2) merumuskan model bimbingan pribadi agar siswa memiliki persepsi positif tentang matematika, (3) merumuskan bimbingan belajar yang tepat agar siswa dapat mengerjakan soal matematika dengan tekun (resilien), (4) mengevaluasi pelaksanaan bimbingan pribadi dan belajar yang sudah diberikan kepada siswa.

\section{METODE PELAKSANAAN}

Pelaksanaan kegiatan pengabdian ini dibagi dalam tiga tahapan, yaitu tahap persiapan, tahap pelaksanaan, tahap evaluasi. Ketiga tahap tersebut dilakukan supaya siswa memiliki sikap resilien sebelum menempuh ujian nasional SD pada bulan April 2019.

\section{Tahap Persiapan}

Pada tanggal 15 Januari 2019 Ibu Ignatia Esti Sumarah bersama wakil kepala sekolah bidang kesiswaan SD Cahaya Bangsa Utama mencoba menyusun assessment untuk mengetahui akar permasalahan siswa. Ada dua pertanyaan yang dirumuskan agar dapat dijawab siswa, yaitu: (1) Bagaimana persiapanmu dalam menghadapi Ujian Nasional, 
khususnya untuk mata pelajaran matematika?, (2) Apa yang kamu rasakan selama musim try out ini?

Pada tanggal 16 Januari, Bapak Yustinus Budi Setiawan dan Devina Anky Arifania (guru kelas 6) mengajukan dua pertanyaan dengan menggunakan teknik Reflective Listening. Maksudnya, memanggil setiap siswa secara pribadi dan memberi kesempatan untuk menjawab setiap butir pertanyaan dengan cara berceritera. Wakil kepala sekolah bidang kesiswaan dan guru kelas 6 mendengarkan dengan penuh empati untuk mengetahui akar permasalahan siswa (Athos and Gabarro, 1978). Siswa pun menjadi merasa nyaman untuk menjawab pertanyaan-pertanyaan tersebut.

Jawaban-jawaban para siswa kemudian diolah dalam perspektif Explanatory Style atau teori yang menganalisis cara pandang seseorang dalam memaknai peristiwa (baik positif maupun negatif). Ada tiga dimensi untuk memaknai peristiwa tersebut, yaitu permanence, pervasiveness, dan personalization (Seligman, 2011). Tiga dimensi tersebut dapat dijadikan acuan untuk membantu siswa sanggup mengubah cara pandangnya dalam memaknai peristiwa negatif menjadi positif.

Dimensi Permanence mengacu pada pola pikir siswa jika kesulitannya dalam mengerjakan soal matematika akan terus terjadi dan tidak dapat ia atasi. Apabila pola pikir tersebut tidak berubah, maka tingkat resiliennya menjadi rendah. Cara pandang tersebut dapat berubah apabila siswa memahami makna matematika dalam hidup.

Dimensi Pervasiveness berarti menyebar/menglobal, mengacu pada pola pikir siswa bahwa ia mengalami kesulitan pada seluruh materi pelajaran matematika. Siswa yang tidak pervasive hanya akan mengalami kesulitan di bagian tertentu saja dari mata pelajaran matematika (misalnya siswa mengalami kesulitan memahami konsep matematika bangun ruang, tetapi ia mampu mengerjakan soal KPK/FPB)

Dimensi Personalization menunjukkan pola pikir siswa yang menyikapi penyebab kesulitan matematika yang dialaminya karena menganggap dirinya memang tidak kompeten dalam matematika. Sebaliknya, siswa yang memiliki daya juang tinggi mengetahui kesulitan matematika disebabkan oleh faktor-faktor di luar dirinya sehingga dia dapat melakukan upaya untuk memperbaikinya.

Ibu Ignatia Esti Sumarah membimbing Bapak Yustinus Budi Setiawan untuk dapat memasukkan data-data permasalahan siswa tersebut ke tabel dimensi teori explanatory style berikut: 


\begin{tabular}{|c|c|c|c|c|c|c|c|}
\hline \multirow[t]{2}{*}{ No } & \multirow[t]{2}{*}{ Nama } & \multicolumn{2}{|c|}{ Permanence } & \multicolumn{2}{|c|}{ Pervasiveness } & \multicolumn{2}{|c|}{ Personalization } \\
\hline & & Ya & Tdk & $\mathbf{Y a}$ & Tdk & $\mathbf{Y a}$ & Tdk \\
\hline 1 & Qn & $\mathrm{V}$ & & & $\mathrm{X}$ & & $\mathrm{X}$ \\
\hline 2 & $\mathrm{Nc}$ & $\mathrm{V}$ & & & $\mathrm{X}$ & & $\mathrm{X}$ \\
\hline 3 & Fh & $\mathrm{V}$ & & & $\mathrm{X}$ & & $\mathrm{X}$ \\
\hline 4 & $\mathrm{Nh}$ & $\mathrm{V}$ & & & $\mathrm{X}$ & & $\mathrm{X}$ \\
\hline 5 & $\mathrm{Vn}$ & $\mathrm{V}$ & & $\mathrm{V}$ & & & $\mathrm{X}$ \\
\hline 6 & Ry & $\mathrm{V}$ & & $\mathrm{V}$ & & $\mathrm{V}$ & \\
\hline 7 & By & $\mathrm{V}$ & & $\mathrm{V}$ & & $\mathrm{V}$ & \\
\hline 8 & $\mathrm{Al}$ & $\mathrm{V}$ & & $\mathrm{V}$ & & $\mathrm{V}$ & \\
\hline 9 & Dr & $\mathrm{V}$ & & & $\mathrm{X}$ & $\mathrm{V}$ & \\
\hline 10 & Gs & & $\mathrm{X}$ & & $\mathrm{X}$ & & $\mathrm{X}$ \\
\hline 11 & $\mathrm{Ar}$ & $\mathrm{V}$ & & & $\mathrm{X}$ & $\mathrm{V}$ & \\
\hline 12 & $\mathrm{An}$ & $\mathrm{V}$ & & $\mathrm{V}$ & & $\mathrm{V}$ & \\
\hline 13 & $\mathrm{Hn}$ & & $\mathrm{X}$ & & $\mathrm{X}$ & & $\mathrm{X}$ \\
\hline Jml & & 12 & & 5 & & 6 & \\
\hline
\end{tabular}

Dari tabel tersebut, diketahui ada 12 siswa yang memiliki pola pikir berdimensi permanence. Mereka berpikir kesulitan dalam mengerjakan soal-soal matematika akan terus berulang (lagi dan lagi) dan tidak dapat ia atasi. Data tersebut menunjukkan jika siswa kelas 6 memerlukan bimbingan agar mereka dapat mengubah pola pikirnya bahwa permasalahannya yang berkaitan dengan pengerjaan soal-soal matematika, dapat ia atasi.

Dari hasil diskusi dengan Bapak Yustinus Budi Setiawan, disepakati: (1) wakil kepala sekolah bidang kesiswaan (Bapak Yustinus Budi Setiawan) akan memberikan bimbingan pribadi untuk membantu siswa memiliki konsep positif tentang matematika, (2) guru matematika (Ibu Anisa Wilujeng) bekerja sama dengan guru kelas 6 (Ibu Devina Anky Arifania) akan memberikan bimbingan belajar agar siswa memiliki cara efektif mengerjakan soal matematika.

\section{Tahap Pelaksanaan}

Pada tanggal 21 Januari 2019, wakil kepala sekolah bidang kesiswaan memberikan bimbingan pribadi kepada seluruh siswa kelas 6. Caranya: menanyai siswa satu persatu tentang cita-citanya. Kemudian mengajak siswa ybs untuk berpikir bahwa cita-citanya tersebut membutuhkan kemampuan matematis. 


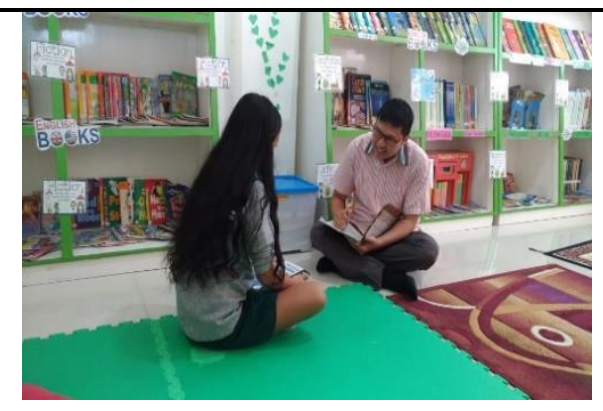

Foto di atas saat Qn menjawab cita-citanya ingin menjadi arsitek agar dapat merancang bangunan. Ia dibimbing untuk menganalis kemampuan apa saja yang perlu dimiliki arsitek supaya dapat merancang bangunan dengan tepat dan akurat. Ia dapat mengungkapkan jika kemampuan berhitung merupakan salah satu syarat yang harus dimiliki oleh seorang arsitek. Qn memiliki pola pikir baru: agar kelak dapat menjadi arsitek handal maka mulai dari sekarang perlu melatih kemampuan matematis. Ia pun termotivasi untuk tekun dan cermat saat mengerjakan soal-soal matematika.

Pada tanggal 28 Februari 2019, guru matematika memberikan bimbingan belajar dengan mengujikan soal cerita/uraian/essay yang terdapat dalam kumpulan soal-soal UN. Ia kemudian mengobservasi cara kerja para siswa dan melihat bahwa mayoritas siswa menjawab terlalu singkat dan hanya mencantumkan angka-angka sebagai jawabannya tanpa menuliskan langkah-langkah menemukan jawaban tersebut. Kemudian guru memberikan informasi berkaitan dengan soal cerita/uraian/essay sebagai berikut: (a) skor nilai pilihan ganda adalah 70\%, sedangkan soal cerita/uraian/essay 30\%, (b) 30 menit pertama harus digunakan untuk mengerjakan soal cerita/uraian/essay, (c) 90 menit berikutnya mengerjakan soal pilihan ganda, (d) jawaban untuk soal cerita/uraian/essay harus disertai dengan menuliskan langkah-langkahnya, (e) setelah mengerjakan soal cerita/uraian/essay dilanjutkan dengan mengerjakan soal pilihan ganda yang paling mudah, dilanjutkan untuk menjawab soal yang tingkat kesulitannya sedang, dan terakhir yang paling susah. Alasannya, karena skor nilai untuk soal pilihan ganda yang mudah-sedang-susah: sama.

Pada minggu pertama di bulan Maret, guru matematika bekerjasama dengan guru kelas 6 rutin memberikan bimbingan belajar. Caranya siswa dibagi dalam kelompok-kelompok kecil. Siswa yang sudah bisa mencapai nilai tinggi disandingkan dengan yang siswa-siswa lainnya yang nilainya sedang. Guru matematika kemudian menghandle beberapa siswa yang nilainya masih rendah, untuk diberi penjelasan secara lebih rinci, seperti dalam foto berikut: 


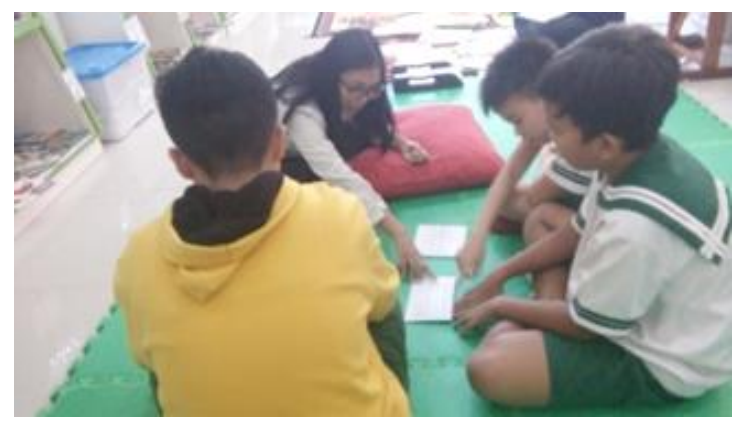

Sementara itu guru kelas 6 menghandle siswa yang nilainya sudah cukup baik (kunci jawaban sudah disiapkan guru matematika dan diberikan kepada guru kelas untuk dijadikan pedoman jika siswa mengalami kebingungan). Bagi siswa yang pencapaian nilainya masih rendah, guru memfokuskan pada soal-soal yang mudah terlebih dahulu. Tujuannya agar siswa dapat menguasai soal yang mudah tersebut terlebih dahulu sambil membimbing secara intensif satu-persatu.

Guru matematika membahas soal-soal try out dan UN, dimulai dengan membahas soal cerita/uraian/essay. Pertimbangannya karena soal uraian berbentuk penalaran, jadi siswa harus dibiasakan untuk dapat menganalisis soal tersebut. Guru juga melakukan analisis atas setiap butir soal untuk mengetahui pada soal bagian mana yang masih banyak dijawab salah oleh siswa.

\section{Tahap Evaluasi}

Ibu Ignatia Esti Sumarah bersama Bapak Yustinus Budi Setiawan melakukan evaluasi atas proses bimbingan yang sudah diberikan. Hasilnya: bimbingan pribadi yang diberikan oleh wakil kepala sekolah, siswa menjadi bersemangat dalam mengerjakan soal matematika. Hal tersebut dapat terjadi karena mereka mengalami perubahan pola pikir dalam memaknai peristiwa mengerjakan soal-soal matematika. Pemaknaan peristiwa ini didapatkan setelah mengetahui adanya keterkaitan antara cita-citanya dengan pentingnya memiliki kemampuan matematis yang perlu mereka kuasai sedari sekarang.

Dari bimbingan belajar yang diberikan oleh guru matematika dan guru kelas 6, siswa mengetahui grafik individu dan perkembangan belajar mereka. Siswa diajak untuk menghargai proses. Proses yang baik biasanya menunjukkan kenaikan, sekecil apapun itu. Siswa juga diingatkan untuk tidak membandingkan dengan teman yang lain. Selain itu, siswa juga dapat melihat adanya peningkatan nilai matematika dari try out pertama sampai ketujuh. 
Hasil nilai try out yang dilaksanakan dari bulan Januari hingga April dan diakhiri dengan UN yang dilaksanakan April 2019 dapat dilihat pada tabel berikut:

\begin{tabular}{|c|c|c|}
\hline No & Jenis Try Out dan UN & $\begin{array}{c}\text { Rata-rata kelas untuk } \\
\text { mapel matematika }\end{array}$ \\
\hline 1 & TRY OUT BKS KELURAHAN & 44,42 \\
\hline 2 & TRY OUT KABUPATEN 1 & 46.42 \\
\hline 3 & TRY OUT SDSN KECAMATAN & 53.05 \\
\hline 4 & TRY OUT KABUPATEN 2 & 56.32 \\
\hline 5 & TRY OUT K3S KECAMATAN 1 & 54.31 \\
\hline 6 & TRY OUT KABUPATEN 3 & 52.05 \\
\hline 7 & TRY OUT K3S KECAMATAN 2 & 63,27 \\
\hline 8 & UJIAN NASIONAL (UN) & \\
\hline
\end{tabular}

Dari tabel tersebut, nampak adanya peningkatan nilai rata-rata try out matematika. Bahkan nilai rata-rata UN matematika mencapai skor 63,27. Skor tersebut termasuk ke dalam kategori sangat memuaskan (sebab nilai KKM UN untuk mapel matematika adalah 4). Peningkatan ini terjadi karena siswa memiliki sikap resilien atau daya juang dalam mengerjakan soal-soal matematika, setelah siswa diberikan bimbingan pribadi dan bimbangan belajar.

Dengan demikian, evaluasi terhadap pelaksanaan pendampingan penerapan bimbingan pribadi dan belajar yang diberikan kepada siswa kelas 6 SD Cahaya Bangsa Utama terbukti efektif, sebab para siswa menjadi: (1) memiliki persepsi positif tentang matematika yang bermanfaat bagi kehidupan sehari-hari, (2) memiliki sikap resilien atau bersemangat dan tekun mengerjakan soal-soal matematika.

\section{HASIL DAN PEMBAHASAN}

Bimbingan adalah proses untuk membantu siswa untuk memahami dirinya sendiri serta mencapai produktivitas akademik yang optimal. Bimbingan di sekolah perlu menitikberatkan pada segenap upaya untuk membantu siswa memiliki motivasi belajar. Siswa yang memiliki kesulitan belajar perlu didampingi untuk dapat mengatasi kesulitannya dalam belajar; sedangkan siswa yang lambat belajar hendaknya dibantu untuk mau belajar sebanyak mungkin; sehingga semua siswa terlibat dalam proses pembelajaran (Furgon, 2005: 13). Dalam SK Menpan No.83/1993, ditegaskan bahwa selain tugas utama mengajar, 
guru sekolah dasar memiliki tugas tambahan untuk menyusun program bimbingan di kelasnya.

Oleh karena itu, menurut Rochman Natawidjaja (1987) ada beberapa hal yang perlu dilakukan guru untuk memberikan bimbingan dalam rangka proses belajar mengajar, yakni: (a) mengembangkan iklim kelas yang bebas dari ketegangan dan yang bersuasana membantu perkembangan siswa, (2) mempelajari dan membantu siswa menemukan kekuatan, kelemahan, kebiasaan dan kesulitan yang dihadapinya, (3) memberikan pengarahan atau orientasi dalam rangka belajar yang efektif. Ketiga point tersebut menjadi acuan dosen PGSD untuk memberikan pengabdian kepada wakil kepala sekolah bagian kesiswaan, guru kelas 6, dan guru matematika di SD Cahaya Bangsa Utama.

Point nomor 1 , menjadi dasar dosen PGSD untuk memberikan pendampingan kepada wakil kepala sekolah bagian kesiswaan, guru kelas 6, dan guru matematika melakukan assesment kepada 13 siswa kelas 6. Dari hasil assessment yang diolah dalam perspektif Explanatory Style, diketahui ada 12 siswa yang memiliki pola pikir berdimensi permanence. Mereka berpikir kesulitan dalam mengerjakan soal-soal matematika akan terus berulang (lagi dan lagi) dan tidak dapat ia atasi. Data tersebut menunjukkan jika siswa kelas 6 memerlukan bimbingan agar mereka dapat mengubah pola pikirnya bahwa ia dapat mengerjakan soal matematika.

Point nomor 2 dan 3 menjadi acuan dosen PGSD untuk memberi saran kepada wakil kepala sekolah bagian kesiswaan, guru kelas 6, dan guru matematika untuk membantu siswa kelas 6 MENGUBAH pola pikirnya tentang matematika. Esensi point 2 tentang perlunya guru menemukan kekuatan dan kesulitan yang dihadapinya (dalam hal ini sulit mengerjakan soal-soal matematika), menjadi dasar bagi wakil kepala sekolah bidang kesiswaan untuk memberikan bimbingan pribadi Akibatnya, siswa kelas 6 menjadi memiliki konsep positif tentang matematika, karena dikaitkan dalam konteks (pencapaian) citacitanya.

Point 3 tentang perlunya guru memberikan pengarahan atau orientasi dalam rangka membantu siswa dapat belajar secara efektif, direalisasikan oleh guru kelas 6 dan guru matematika untuk memberikan bimbingan belajar matematika. Para siswa akhirnya mengetahui langkah-langkah efektif dalam mengerjakan soal matematika.

Bimbingan pribadi dan bimbingan belajar matematika yang diberikan berlandaskan pada teori growth mindset atau pola pikir tumbuh. Orang yang memiliki growth mindset menganggap bahwa talenta dan keahlian bukan suatu bawaan sejak lahir, namun dapat 
diasah, dilatih, dipelajari (Dweck, 2006). Lawan growth mindset adalah fixed mindset (pola pikir tetap) yang mengarah pada label diri: "aku tidak mampu/bisa atau bodoh", atau "aku pintar dan aku berbakat". Teori growth mindset membantu siswa bersedia mengerjakan soalsoal matematika (=menerima dan mengatasi kesulitan yang dialaminya), sebab mereka yakin hal tersebut melatih/mengasah kompetensi matematisnya (jadi siswa yakin jika ia tidak bodoh secara matematis).

Bimbingan pribadi dan belajar yang diberikan membantu siswa kelas 6 MENGUBAH pola pikir dari fixed mindset ke growth mindset. Keharusan mengerjakan soal-soal matematika dalam metode drilling dimaknai sebagai suatu tantangan yang dapat membantu mereka mengasah atau mengembangkan kemampuan matematisnya. Perubahan pola pikir ini juga menentukan peningkatan sikap resilien para siswa. Resilien berasal dari kata Latin resilire, yang berarti melambung kembali. Dalam fisika, resilien dikaitkan dengan elastisitas, yaitu kemampuan suatu benda untuk kembali seperti semula setelah diregangkan atau dibengkokkan (McIntosh and Shaw, 2017). Makna yang serupa seperti dalam fisika, resilien adalah kemampuan seseorang untuk bertahan dalam situasi sulit sekaligus mampu dengan mudah menyesuaikan diri untuk mengubah keadaan (Reivich\&Shatte, 2002). Resilien terlihat pada saat seseorang menjalani pengalaman yang sulit, dan tahu bagaimana menghadapi atau beradaptasi dengannya. Kesulitan atau tantangan yang dihadapi itu justru dapat memperkuat ketahanan mentalnya (Grotberg, 1999). Berkat bimbingan pribadi dan belajar, siswa kelas 6 tidak lagi merasa terbebani menjalani try out dan menghadapi UN.

Mengajak para siswa untuk menceriterakan cita-citanya (saat bimbingan pribadi) menjadi titik balik terjadinya perubahan pola pikir. Mereka menyadari bahwa ada keterkaitan antara matematika dengan pencapaian cita-cita tersebut. Cita-cita yang disebutkan oleh siswa seperti menjadi dokter, arsitek, businessman, manajer perusahaan, manajer sepak bola, programmer, dan atlit sepak bola; tentu membutuhkan kemampuan matematis. Oleh karena itu mereka menjadi bersemangat saat mengerjakan soal-soal matematika.

Seperti yang dikatakan oleh Rochman Natawidjaja (1987), salah satu bimbingan yang perlu dilakukan oleh guru adalah memberikan pengarahan atau orientasi dalam rangka belajar yang efektif. Setelah siswa diberi bimbingan pribadi dan belajar, siswa menjadi paham bahwa setiap orang perlu memiliki impian (goal) di masa depan, dan yang 
menentukan setiap orang mampu meraih cita-citanya bukanlah bakat alami, tetapi ketekunan, juga ketekunan mengerjakan soal matematika.

Perubahan pola pikir tersebut tentu membutuhkan memerlukan proses berkelanjutan. Siswa yang sudah bersemangat dalam mengerjakan matematika, sewaktu-waktu dapat menyerah karena menemukan tipe soal matematika yang sulit atau belum pernah dikenali sebelumnya. Dalam kondisi seperti ini guru kelas 6 dan guru matematika bertugas untuk mengingatkan kembali para siswa akan cita-citanya. Harapannya, mereka memahami bahwa proses pencapaian cita-cita tersebut tidak ada yang instan, tetapi perlu ketekunan dan perjuangan tanpa henti. Dengan demikian, siswa mewujudkan sikap tahan uji untuk menghadapi kesulitan (dalam memecahkan soal matematika yang sulit). Hal ini sesuai dengan pendapat Grotberg (1999), bahwa kesulitan atau tantangan yang dihadapi seseorang justru akan memperkuat ketahanan mentalnya untuk menjadi pribadi yang tangguh/punya daya juang/resilien.

Dalam proses jatuh bangun yang dialami siswa tersebut, guru juga harus memiliki growth mindset. Maksudnya, guru kelas 6 bersama guru matematika selalu berupaya memotivasi siswa memiliki keinginan untuk terus mencoba dan tidak memberi label "siswa bodoh" atau "siswa tidak bisa". Di rumah, orang tua siswa juga disarankan untuk melakukan hal yang sama. Dengan demikian, guru dan orang tua menciptakan suasana belajar yang bebas dari ketegangan sehingga membantu perkembangan siswa (Rochman Natawidjaja 1987).

Salah satu contoh iklim kelas yang bersuasana membantu perkembangan siswa adalah pemaparan oleh guru kelas 6 tentang grafik individu yang berisi perkembangan skor try out. Melalui grafik tersebut, siswa diingatkan bahwa skor tersebut tidak dimaksudkan untuk dibanding-bandingkan antara satu siswa dengan yang lain, melainkan agar mereka dapat melihat adanya peningkatan kemampuan (walaupun hanya sedikit). Harapannya, siswa terdorong untuk lebih bekerja keras dan menghargai upaya diri sendiri.

\section{KESIMPULAN}

Pendampingan ini telah memfasilitasi wakil kepala sekolah bidang kesiswaan dapat menerapkan bimbingan pribadi dan bimbingan belajar matematika kepada siswa kelas 6 SD Cahaya Bangsa Utama, dibantu oleh guru kelas 6, dan guru matematika. Para siswa kelas 6 menjadi memiliki cara pandang positif terhadap matematika dan bersemangat mengerjakan soal-soal matematika (=bersikap resilien) dalam rangka mempersiapkan diri menghadapi $\mathrm{UN}$. 


\section{REKOMENDASI}

Pendampingan ini dapat menjadi dasar acuan bagi guru SD untuk memberi bimbingan pribadi dan belajar kepada siswa kelas 6 agar mereka bersikap resilien/berdaya juang untuk siap menghadapi UN.

\section{DAFTAR PUSTAKA}

Abramson, L. Y., Seligman, M. E. P., \& Teasdale, J. D. (1978). Learned Helplessness in Humans: Critique and Reformulation. Journal of Abnormal Psychology, 87(1), 49-74.

Athos, A.G. \& Gabarro, J.J. (1979). Teaching Interpersonal Behavior: to Accompany Interpersonal Behavior, Communication, and Understanding in Relationships. New Jersey: Prentice-Hall.

Furqon (Ed.). (2015). Konsep dan Aplikasi Bimbingan dan Konseling di Sekolah Dasar. Bandung: Pustaka Bani Quraisy.

Jacobs, G.M \&Toh-Heng, H.L. (2013). Small Steps Towards Student-Centered Learning. Mandal (Ed.). Proceedings of the International Conference on Managing the Asian Century (Chapter 7). Singapore: Springer Science+business Media. Page 55-64

Dweck, C. S. 2006. Mindset: The New Psychology of Success. New York: Random House.

Grotberg, E. 1999. Tapping Your Inner Strength: How to Find the Resilience to Deal with Anything. Oakland, CA: New Harbinger Publications, Inc.

McIntosh, R. \& Shaw, J. 2017. Student Resilience: Exploring the Positive Case for Resilience. Bristol: Unite Students.

Noble, P.L.2012. The Making of The IPC: a Personal View. Dalam Taking The IPC Forward, Engaging With The International Primary Curriculum. Woodbridge: John Catt Educational Ltd.

Pletser, J. 2012. International-mindedness and the IPC. Dalam Taking The IPC Forward, Engaging With The International Primary Curriculum. Woodbridge: John Catt Educational Ltd.

Reivich, K. And Shatte, A. 2002. The Resilience Factor: 7 Essensial Skills for Overcoming Life's Inevitable Obstacles. New York: Broadway Books.

Thomas, J.W., Mergendoller, J.R., \&Michaelson, A. 1999. Project Based Learning: a Handbook for Middle and High School Teachers. Novato, CA: The Buck Institute for Education

Rochman Natawidjaja. 1987. Program dan Bimbingan Penyuluhan di Sekolah. Jakarta: Depdikbud.

Seligman, M.E. 2001. Learned Optimism: How to Change Your Mind and Your Life. New York: Vintage. 